\title{
Desempenho agronômico de cultivares de trigo para safrinha no Planalto de Santa Catarina, Brasil
}

\author{
Agronomic performance of wheat cultivars for off-season in the Santa Catarina Plateau, \\ Brazil
}

\author{
Samuel Luiz Fioreze*, James Cruz Oliveira, Volni Mazzuco, Ana Flávia Wuaden, Robson Pelissari \\ Drun
}

Universidade Federal de Santa Catarina, Curitibanos, SC, Brasil. Autor para correspondência: s.fioreze@ufsc.br

Submissão: 29/08/2019 / Aceite: 06/03/2020

\begin{abstract}
RESUMO
O aumento na produção brasileira de trigo para suprir a demanda interna do cereal está associado ao aumento da área de cultivo em regiões ou épocas historicamente pouco exploradas. Neste sentido, o presente trabalho teve como objetivo estudar o desempenho produtivo de cultivares de trigo para cultivo em safrinha na região do Planalto Catarinense. O experimento de campo foi conduzido entre os meses de fevereiro e junho de 2018. Cinco cultivares de trigo (BRS 264, BRS 394, BRS Parrudo, Tbio Audaz e Tbio Sonic) foram semeadas em 14 de fevereiro e 01 de março. Os parâmetros morfológicos das plantas foram determinados no período de antese. No período de maturação, foram determinados os componentes da produção e produtividade de grãos. Adicionalmente, determinou-se a duração do período entre emergência e florescimento e entre florescimento e maturação das plantas. A cultivar BRS Parrudo não apresentou desenvolvimento satisfatório para cultivo em safrinha, com sintomas de anomalias na formação da espiga. As demais cultivares estudadas apresentaram crescimento e produção de grãos satisfatória para a semeadura realizada em 14 de fevereiro.
\end{abstract}

PALAVRAS-CHAVE: Triticum aestivum, zoneamento agrícola, temperatura, produtividade.

\begin{abstract}
The increase in Brazilian wheat production to supply the domestic demand is associated with the increase of the cultivated area in historically unexplored regions or seasons. In this sense, this paper aimed to study the yield performance of wheat cultivars in off-season conditions in the Santa Catarina Plateau, in the state of Santa Catarina, Brazil. The field experiment was carried out from February to June 2018. Five wheat cultivars (BRS 264, BRS 394, BRS Parrudo, Tbio Audaz, and Tbio Sonic) were sown on February $14^{\text {th }}$ and March $1^{\text {st }}$. The morphological parameters of the plants were determined at the anthesis stage. Production components and grain productivity were determined at the maturation stage. In addition, the duration of the period between emergence and flowering and between flowering and maturation was determined. The 'BRS Parrudo' cultivar did not develop satisfactorily for off-season cropping, showing anomalies on cob formation. The remaining cultivars studied presented satisfactory growth and grain yield when sown on February $14^{\text {th }}$.
\end{abstract}

KEYWORDS: Triticum aestivum, agricultural zoning, temperature, yield.

\section{INTRODUÇÃO}

A expansão das áreas de produção de trigo no Brasil é de suma importância, tendo em vista que o país é, historicamente, um dos maiores importadores mundiais do cereal (FAO 2018). Apesar da grande dependência da importação de trigo, o Brasil possui um enorme potencial para aumentar a produção do grão. Considerando-se os cenários apresentados por PASINATO et al. (2018), o Brasil apresenta um potencial para sair da condição de importador e até mesmo se tornar um exportador de trigo. Este cenário tem contemplado o avanço das áreas de produção de trigo na região do Cerrado brasileiro principalmente em áreas acima de $800 \mathrm{~m}$ de altitude (PASINATO et al. 2018), onde as temperaturas são mais amenas, ou mesmo para o cultivo em ambiente irrigado (CARGNIN et al. 2008, SÓ e SILVA et al. 2008). Complementarmente, o aumento na produção nacional poderia ocorrer pelo aumento das áreas de cultivo 
no Sul do Brasil em épocas já delimitadas pelo zoneamento agrícola de risco climático (BRASIL 2019).

Além da possibilidade de aumento da produção de trigo no bioma Cerrado ou mesmo em regiões tradicionais de cultivo, outras regiões possuem potencial para expansão de áreas de cultivo. Embora atualmente responda por aproximadamente $90 \%$ da produção nacional de trigo (CONAB 2019), a região Sul do Brasil, onde estão localizadas as regiões I e II de Valor de Cultivo e Uso (CUNHA et al. 2006), ainda possui janelas de cultivo pouco aproveitadas em termos de produção, o que pode levar à possibilidade de exploração. A colheita da safra de verão, cuja principal cultura tem sido a soja, costuma ser realizada entre os meses de fevereiro e março nos estados do Sul, principalmente para cultivares com ciclo precoce. Considerando que os municípios com clima mais frio possuem elevado risco para o cultivo de milho safrinha (BRASIL 2019), a cultura do trigo poderia ser uma opção para cultivo entre os meses de fevereiro e maio.

O avanço da cultura do trigo na região de Cerrado tem como uma das principais ferramentas os programas de melhoramento genético. Características associadas a redução de ciclo, tolerância a altas temperaturas e ao alumínio tóxico, restrições hídricas e mesmo a doenças como a Brusone (Pyricularia oryzae) são de fundamental importância, haja vista que são os principais limitantes para o cultivo neste ambiente (CARGNIN et al. 2006, MACIEL 2011, POERSCH-BORTOLON et al. 2016, KUMAR et al. 2017, PEREIRA et al. 2019). Várias dessas características possuem importância na adaptação de cultivares de trigo para cultivo em safrinha na região Sul do Brasil, com destaque para a tolerância a altas temperaturas e o ciclo reduzido, considerando o risco de geadas no final do outono.

Destacando a necessidade de aumento na produção nacional de trigo e o potencial de adaptação de cultivares para o cultivo fora da época tradicional de semeadura para o sul do Brasil, o presente trabalho teve como objetivo estudar o desempenho produtivo de cultivares de trigo para cultivo em safrinha na região do Planalto Catarinense.

\section{MATERIAL E MÉTODOS}

O experimento foi conduzido em condições de campo, entre os meses de fevereiro e junho de 2018, na Fazenda Experimental Agropecuária da Universidade Federal de Santa Catarina, no município de

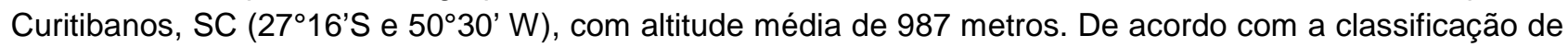
Köppen-Geiger, o clima da região é do tipo $\mathrm{Cfb}$, com temperatura média entre $15^{\circ} \mathrm{C}$ e $25^{\circ} \mathrm{C}$ e precipitação média anual de $1500 \mathrm{~mm}$ (CLIMATE-DATA 2019). Na Figura 1 são apresentados os dados de temperatura e precipitação pluvial no período de condução do experimento. O solo experimental é classificado como Cambissolo Háplico de textura argilosa (SANTOS et al. 2018) e apresentava as seguintes características: $33 \mathrm{~g} \mathrm{dm}^{-3}$ de matéria orgânica; $\mathrm{pH}(\mathrm{CaCl}) 6,7 ; 13,3 \mathrm{mmol}_{\mathrm{c}} \mathrm{dm}^{-3}$ de Ca; $5,2 \mathrm{mmol}_{\mathrm{c}} \mathrm{dm}^{-3} \mathrm{de} \mathrm{Mg} ; 0,0 \mathrm{cmol}_{\mathrm{c}} \mathrm{dm}^{-3}$ de Al; $0,19 \mathrm{cmol}_{\mathrm{c}} \mathrm{dm}^{-3}$ de $\mathrm{K} ; 13,1 \mathrm{mg} \mathrm{dm}^{-3}$ de $\mathrm{P}$ (Mehlich-1); e Saturação de bases de $87 \%$.
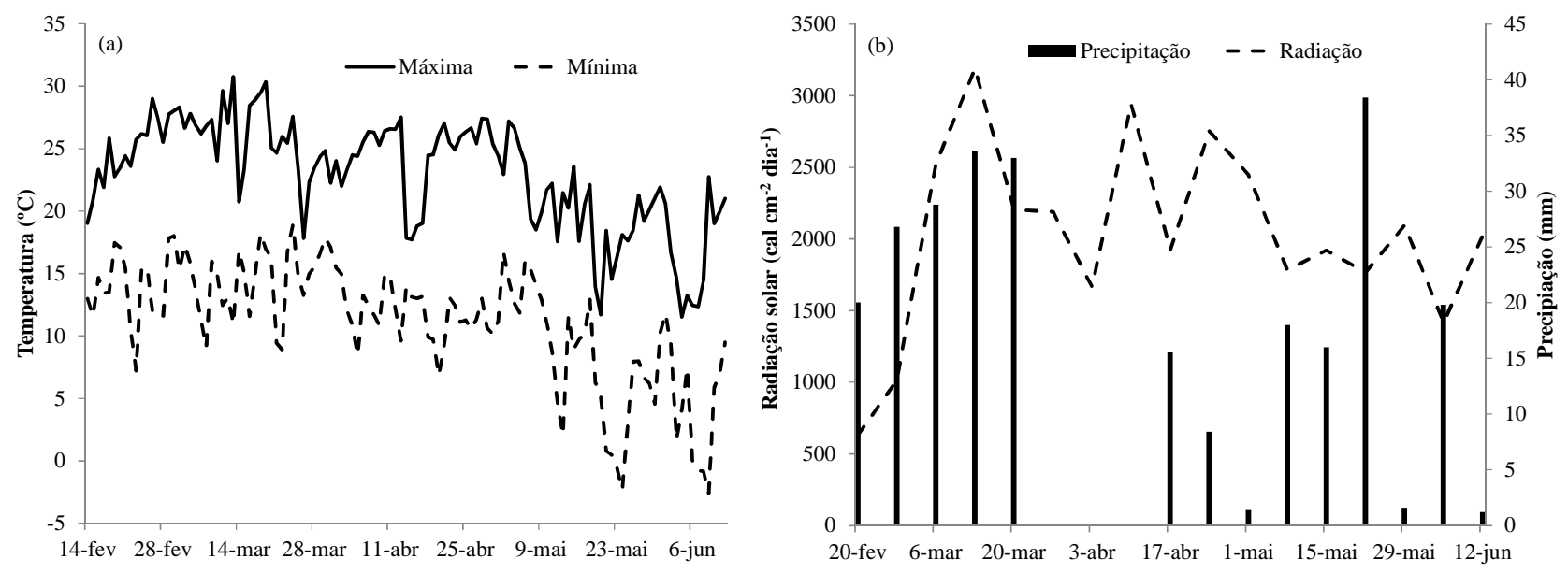

Figura 1. Valores de temperatura máxima e mínima (a) e valores precipitação e radiação solar (b) durante o ciclo de cultivares de trigo cultivadas em safrinha no Planalto Catarinense. Curitibanos, SC, 2018. Dados provenientes do Centro de Informações de Recursos Ambientais e de Hidrometeorologia de Santa Catarina CIRAM/EPAGRI. Estação climática localizada a 50 metros do experimento.

Figure 1. Maximum and minimum temperatures (a), and rainfall and solar radiation values (b) during the growing stage of wheat cultivars for off-season crops in the Santa Catarina Plateau. Curitibanos, SC, 2018. Data obtained from the Centro de Informações de Recursos Ambientais e de Hidrometeorologia de Santa Catarina CIRAM/EPAGRI. Climactic station 50 meters from the experiment location. 
O delineamento experimental utilizado foi o de blocos ao acaso em esquema de parcelas subdivididas com quatro repetições. As parcelas foram compostas por duas épocas de semeadura, 14 de fevereiro e 01 de março de 2018. As subparcelas foram compostas por cinco cultivares de trigo, BRS 264, BRS 394, BRS Parrudo, Tbio Sonic e Tbio Audaz. Cada unidade experimental foi formada por oito linhas de cultivo, espaçadas entre si em 0,17 m e com 1 metro de comprimento, com uma densidade de 411 sementes por metro quadrado. As seis linhas centrais foram consideradas como parcela útil.

O experimento foi conduzido em sistema de cultivo convencional, tendo o alho como cultura antecessora. A adubação de base foi incorporada manualmente, utilizando-se $450 \mathrm{~kg} \mathrm{ha}^{-1}$ do fertilizante formulado 04-18-08 (NPK). A abertura das linhas e a semeadura foram realizadas de forma manual. As sementes foram tratadas com fungicida/inseticida de ação protetora à base de Piraclostrobina+Tiofanato metílico+Fipronil (Standak $\operatorname{Top}^{\circledR}$ ). A adubação de cobertura foi realizada com $120 \mathrm{~kg} \mathrm{ha}^{-1}$ de nitrogênio, na forma de ureia (45\% de N). A dose total foi dividida em duas aplicações, nos estádios 3 e 6 da escala fenológica de Feeks e Large (LARGE 1954), caracterizadas pelo início da fase de perfilhamento e alongamento do colmo, respectivamente. O manejo de plantas daninhas foi realizado de forma manual, de acordo com a necessidade. O complemento do manejo fitossanitário foi realizado com aplicações de inseticida (Imidacloprido+Beta-ciflutrina) e fungicida (Propiconazol) nos estádios 6 e 10.5 (antese) da escala fenológica de Feeks e Large (LARGE 1954).

A duração do período entre emergência e antese foi determinada para as duas épocas de semeadura. Contudo, em virtude da ocorrência de geadas (Figura 1), a duração do período entre antese e maturação foi determinada apenas para a primeira época de semeadura. No período de antese, plantas de duas linhas inteiras de cada subparcela foram coletadas para determinação dos parâmetros biométricos. Foram determinados o número de colmos e de espigas por metro quadrado e a massa de matéria seca de colmos+bainhas, folhas e espigas, com os quais se determinou a massa de matéria seca total de plantas por metro quadrado. Na fase de maturação, 15 espigas de cada subparcela foram coletadas ao acaso para determinação do comprimento da ráquis, número de grãos, número de espiguetas (férteis e inférteis) e massa de grãos por espiga. Três linhas de cultivo de cada subparcelas foram coletadas para a determinação do número de espigas por metro quadrado, produtividade de grãos, massa de mil grãos e índice de colheita. Os componentes da produção e produtividade foram avaliados apenas para a primeira época, em virtude dos danos por geada provocados nas plantas da segunda época. Este efeito era esperado, em função das características do estudo.

Os dados foram submetidos à análise de variância pelo teste $F(p<0,05)$. A comparação de médias, quando necessária, foi realizada pelo teste t de Student $(p<0,05)$ para o efeito de épocas de semeadura e pelo teste de Tukey para a comparação entre cultivares.

\section{RESULTADOS E DISCUSSÃO}

Em virtude da ocorrência de duas geadas no início do mês de junho (Figura 1), apenas a primeira época de cultivo pode ser colhida, de modo que apenas a duração do período entre emergência e antese da segunda época pode ser avaliada. A cultivar BRS Parrudo, embora classificada como cultivar precoce, não apresentou avanço fenológico esperado quando comparada às demais cultivares estudadas. Plantas de BRS Parrudo permaneceram no estádio vegetativo por um longo período, apresentando espigamento desuniforme com espigas mal formadas (Figura 2). Este comportamento pode estar associado com a ocorrência de temperaturas acima de $25^{\circ} \mathrm{C}$ nas primeiras semanas após a semeadura da primeira época (14 de fevereiro), haja vista que na segunda época o desenvolvimento das plantas foi um pouco mais uniforme. FIOREZE et al. (2019) não observaram efeitos nocivos do termoperíodo 25/16 ํ sobre a duração das fases fenológicas e na formação da espiga de BRS Parrudo em condições controladas. Esses resultados evidenciam que esta cultivar apresenta maior sensibilidade temperaturas acima de $25 \stackrel{\circ}{\circ}$, o que pode estar relacionado com a ausência de vernalização (ROBERTSON et al. 1996, ALBERTO et al. 2009) e com o processo de diferenciação das espiguetas, os quais ocorrem nos primeiros estádios fenológicos (OCHAGAVÍA et al. 2018). Desta forma, a Cultivar BRS Parrudo não foi considerada para a análise estatística no presente estudo.

As cultivares BRS 264 e BRS 394, adaptadas para condição de Cerrado, apresentaram os menores valores de duração do período entre emergência e antese para as duas épocas de semeadura (Figura 3a). A cultivar Tbio Audaz apresentou a maior duração para o período, principalmente para a semeadura em 01 de março. A cultivar Tbio Sonic, classificada como super-precoce, apresentou encurtamento na duração do período para semeadura em 14 de fevereiro, com ciclo semelhante às cultivares de Cerrado. Contudo, a duração do período entre emergência e antese aumentou em 16 dias quando a semeadura foi realizada em 
01 de março. Este comportamento revela uma maior sensibilidade à ocorrência de temperaturas altas da cultivar Tbio Sonic em relação à Tbio Audaz. A maturação de colheita de plantas de trigo semeadas em 14 de fevereiro apresentou pouca variação entre as cultivares estudadas (Figura 3b). Apesar da duração do ciclo completo das plantas ter apresentado pouca variação, deve-se destacar a redução do período entre antese e maturação para a cultivar Tbio Audaz em relação às demais cultivares.

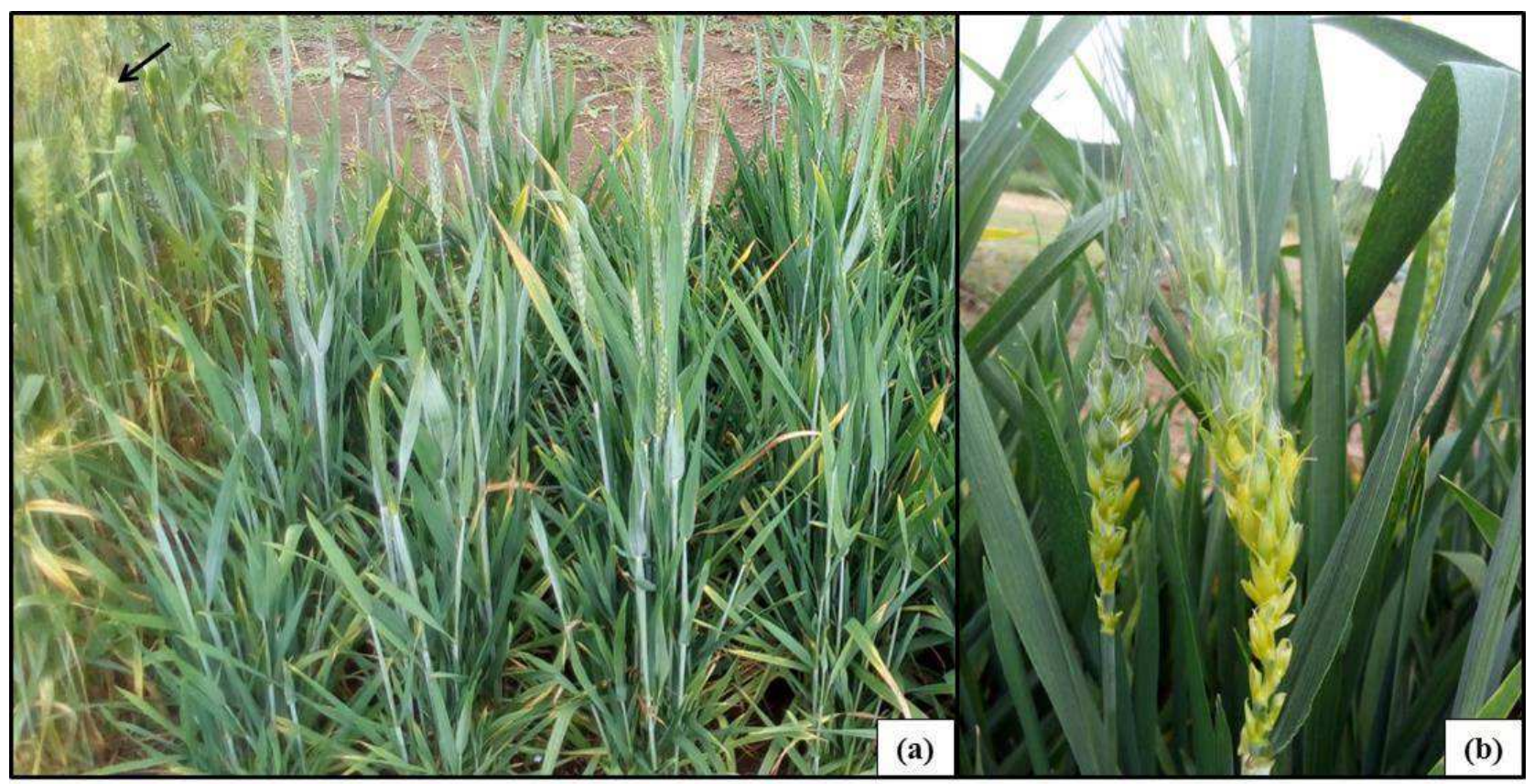

Figura 2. Plantas de trigo, cultivar BRS Parrudo, apresentando atraso fenológico e desuniformidade na emissão de espigas aos 90 dias após a emergência (a) e anomalias na formação da espiga aos 110 dias após a emergência (b). A seta lateral (Figura 2a) indica plantas da cultivar Tbio Audaz com desenvolvimento normal aos 90 dias após a emergência.

Figure 2. Wheat plants of the 'BRS Parrudo' cultivar showing phenological delay and unevenness on cob emission 90 days after emergence (a) and anomalies on cob formation 110 days after emergence (b). The lateral arrow (Figure 2a) indicates plants from cultivar Tbio Audaz with normal development 90 days after emergence.
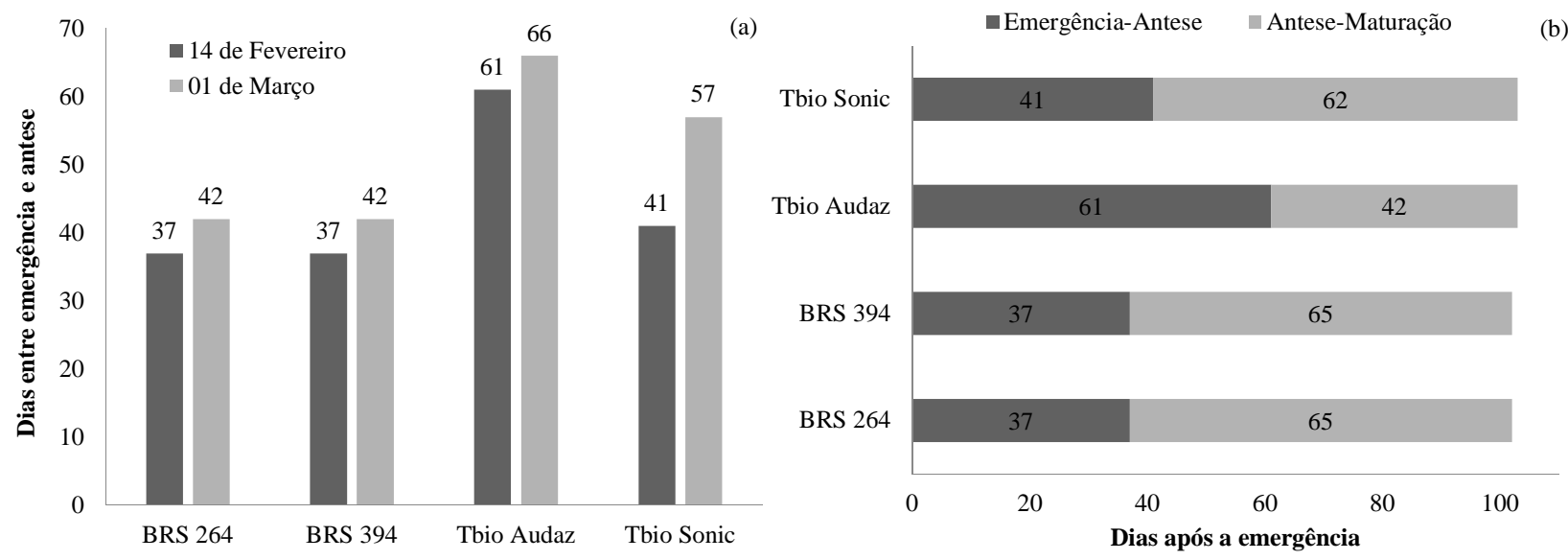

Figura 3. Duração do período entre emergência de plantas e antese (a) e duração total do ciclo (b) de cultivares de trigo cultivadas em safrinha no Planalto Catarinense. Curitibanos, SC, 2018.

Figure 3. Duration of the period between emergence and anthesis (a) and total duration of the cycle (b) of wheat cultivars for off-season crops in the Santa Catarina Plateau. Curitibanos, SC, 2018.

Os parâmetros biométricos de plantas de trigo, avaliados no período de antese, não foram afetados pela época de semeadura de maneira isolada (Tabela 1). $O$ efeito isolado de cultivares foi observado para 0 
número de colmos por metro quadrado, de modo que as cultivares Tbio Audaz e Tbio Sonic foram superiores à BRS 264 e BRS 394. Este resultado é efeito claro da região primária de adaptação das cultivares e sua interação com o processo de perfilhamento, visto que a densidade de semeadura foi constante. Plantas cultivadas em regiões mais frias frequentemente apresentam maior potencial genético de perfilhamento, o qual pode ser afetado por fatores ambientais, como a disponibilidade de água e nutrientes, luz e temperatura (AKTER \& ISLAN 2017, ALMEIDA et al. 2004, VALÉRIO et al. 2009, VALÉRIO et al. 2013, AKTER \& ISLAN 2017). Em contrapartida, cultivares de trigo adaptados para regiões sujeitas à ocorrência de temperaturas mais altas costumam apresentar uma rápida evolução no desenvolvimento do colmo principal, com efeito direto na supressão do perfilhamento. Desta maneira, embora plantas adaptadas a condições de clima quente apresentem algum perfilhamento quando submetidas a temperaturas baixas, seu potencial costuma ser menor do que plantas adaptadas a regiões frias (FIOREZE et al. 2019).

Tabela 1. Parâmetros biométricos de plantas na fase de antese de cultivares de trigo cultivadas em safrinha no Planalto Catarinense. Curitibanos, SC, 2018.

Table 1. Biometric parameters of plants at the anthesis stage of wheat cultivars for off-season crops in the Santa Catarina Plateau. Curitibanos, SC, 2018.

\begin{tabular}{lcclllc}
\hline Época $(\mathrm{E})$ & NC & NESP & MSC & MSF & MSESP & MST \\
\hline 14 de Fevereiro & 749,4 & 466,3 & 343,4 & 147,4 & 129,4 & 620,1 \\
01 de Março & 737,1 & 490,2 & 412,6 & 180,6 & 149,5 & 742,6 \\
\hline$p(E)$ & 0,87 & 0,71 & 0,08 & 0,18 & 0,18 & 0,12 \\
\hline Cultivar (C) & NC & NESP & MSC & MSF & MSESP & MST \\
\hline BRS 264 & $613,9 \mathrm{~b}$ & 395,8 & 314,0 & 128,0 & 129,9 & 571,9 \\
BRS 394 & $577,2 \mathrm{~b}$ & 455,9 & 349,2 & 142,1 & 153,8 & 645,1 \\
Tbio Audaz & $875,0 \mathrm{a}$ & 513,5 & 475,5 & 216,1 & 130,8 & 822,4 \\
Tbio Sonic & $906,8 \mathrm{a}$ & 547,8 & 373,2 & 169,6 & 143,3 & 686,1 \\
\hline$p(\mathrm{C})$ & 0,00 & 0,12 & 0,02 & 0,00 & 0,47 & 0,01 \\
\hline$p(\mathrm{E} \times \mathrm{C})$ & 0,20 & 0,45 & 0,01 & 0,01 & 0,17 & 0,04 \\
\hline $\mathrm{CV}_{1}(\%)$ & 27,7 & 35,2 & 20,4 & 32,6 & 23,2 & 23,2 \\
\hline $\mathrm{CV}_{2}(\%)$ & 21,8 & 26,9 & 19,7 & 22,5 & 24,4 & 20,3 \\
\hline
\end{tabular}

NC: número de colmos por metro quadrado; NESP: número de espigas por metro quadrado; MSC: Massa da matéria seca de colmos $\left(\mathrm{g} \mathrm{m}^{-2}\right)$; MSF: Massa da matéria seca de folhas $\left(\mathrm{g} \mathrm{m}^{-2}\right)$; MSESP: Massa da matéria seca de espigas $\left(\mathrm{g} \mathrm{m}^{-2}\right)$; MST: Massa da matéria seca total $\left(\mathrm{g} \mathrm{m}^{-2}\right)$. $p$ : valor da probabilidade do teste $\mathrm{F} ; \mathrm{CV}_{1}$ : coeficiente de variação da parcela; $\mathrm{CV}_{2}$ : coeficiente de variação da subparcela; Médias seguidas da mesma letra não diferem entre si pelo teste de Tukey $(p<0,05)$.

Foi observada interação entre cultivares de trigo e época de semeadura para os valores de massa de matéria seca de colmos, folhas e a massa de matéria seca total de plantas por metro quadrado no período de antese das plantas (Tabela 1). Para a semeadura realizada em 14 de fevereiro, não houve diferenças entre cultivares de trigo para o acúmulo de matéria seca em colmos, folhas e, consequentemente, para o acúmulo total de matéria seca (Tabela 2). Para a semeadura realizada em 01 de março, a cultivar Tbio Audaz apresentou maior acúmulo de biomassa em relação às demais cultivares. Com isso, Tbio Audaz foi a única, entre as cultivares estudadas, que apresentou aumento significativo no acúmulo de matéria seca entre a primeira e a segunda época de semeadura. Este efeito provavelmente é um reflexo da maior duração do período entre emergência e antese observado para esta cultivar, especialmente na segunda época (Figura 3a), associado com o alto perfilhamento da cultivar (Tabela 1). Esta hipótese é reforçada pelo comportamento intermediário, em termos de acúmulo de matéria seca total, apresentado por Tbio Sonic na segunda época de semeadura (Tabela 2).

O número de espigas por metro quadrado avaliado no período de maturação de plantas de trigo semeadas em 14 de fevereiro não variou entre cultivares (Tabela 3). Embora plantas de Tbio Audaz e Tbio Sonic tenham apresentado maior número de colmos no período de antese, a ausência de diferenças entre cultivares para número de espigas por metro quadrado é explicada pela redução da porcentagem de perfilhos férteis em plantas de Tbio Audaz e Tbio Sonic (Figura 4). A elevada emissão de perfilhos pode levar ao aumento na competição intraespecífica da planta, provocando a senescência de perfilhos emitidos tardiamente (FIOREZE \& RODRIGUES 2012, FIOREZE et al. 2019). Como efeito, plantas com reduzido Rev. Ciênc. Agrovet., Lages, SC, Brasil (ISSN 2238-1171) 
número de perfilhos frequentemente apresentam colmos mais uniformes e bem desenvolvidos, com baixa taxa de abortamento.

Tabela 2. Interação entre época de semeadura e cultivares de trigo para parâmetros biométricos de plantas na fase de antese. Curitibanos, SC, 2018.

Table 2. Interaction between sowing dates and wheat cultivars for biometric parameters of plants in the anthesis stage. Curitibanos, SC, 2018.

\begin{tabular}{llllllc}
\hline & \multicolumn{2}{c}{ MSC } & \multicolumn{2}{c}{ MSF } & \multicolumn{2}{c}{ MST } \\
\hline & 14 de Fevereiro & 01 de Março & 14 de Fevereiro & 01 de Março & 14 de Fevereiro 01 de Março \\
\hline BRS 264 & $291,0 \mathrm{Aa}$ & $337,1 \mathrm{Ab}$ & $118,4 \mathrm{Aa}$ & $137,5 \mathrm{Ab}$ & $535,3 \mathrm{Aa}$ & $608,5 \mathrm{Aa}$ \\
BRS 394 & $371,8 \mathrm{Aa}$ & $326,6 \mathrm{Ab}$ & $144,0 \mathrm{Aa}$ & $140,3 \mathrm{Ab}$ & $678,5 \mathrm{Aa}$ & $611,7 \mathrm{Aa}$ \\
Tbio Audaz & $364,1 \mathrm{Ba}$ & $586,8 \mathrm{Aa}$ & $158,7 \mathrm{Ba}$ & $273,6 \mathrm{Aa}$ & $638,4 \mathrm{Ba}$ & $1006,3 \mathrm{Aa}$ \\
Tbio Sonic & $346,7 \mathrm{Aa}$ & $399,8 \mathrm{Ab}$ & $168,3 \mathrm{Aa}$ & $170,9 \mathrm{Ab}$ & $628,2 \mathrm{Aa}$ & $744,0 \mathrm{Aab}$ \\
\hline
\end{tabular}

MSC: Massa da matéria seca de colmos $\left(\mathrm{g} \mathrm{m}^{-2}\right)$; MSF: Massa da matéria seca de folhas $\left(\mathrm{g} \mathrm{m}^{-2}\right)$; MST: Massa da matéria seca total $\left(\mathrm{g} \mathrm{m}^{-2}\right)$. Médias seguidas da mesma letra, maiúscula, não diferem entre si pelo teste de $t$ de Student $(p<0,05)$ para comparação entre épocas. Médias seguidas da mesma letra, minúscula, não diferem entre si pelo teste de Tukey $(p<0,05)$ para comparação entre cultivares.

Tabela 3. Parâmetros produtivos de cultivares de trigo em safrinha ${ }^{1}$ no Planalto Catarinense. Curitibanos, SC, 2018.

Table 3. Production parameters of wheat cultivars for off-season ${ }^{1}$ crops tin he Santa Catarina Plateau. Curitibanos, SC, 2018.

\begin{tabular}{llllll}
\hline Cultivar & NES & CR & NESP & NESPF & NESPIN \\
\hline BRS 264 & 570,26 & $5,67 \mathrm{~b}$ & $14,30 \mathrm{~b}$ & 12,82 & $1,48 \mathrm{~b}$ \\
BRS 394 & 583,33 & $6,77 \mathrm{a}$ & $15,52 \mathrm{~b}$ & 13,30 & $2,22 \mathrm{~b}$ \\
Tbio Audaz & 547,39 & $6,99 \mathrm{a}$ & $18,23 \mathrm{a}$ & 14,03 & $4,20 \mathrm{a}$ \\
Tbio Sonic & 449,35 & $6,44 \mathrm{ab}$ & $15,37 \mathrm{~b}$ & 12,60 & $2,77 \mathrm{~b}$ \\
\hline $\mathrm{p}$ & 0,26 & 0,02 & 0,00 & 0,20 & 0,00 \\
\hline CV (\%) & 18,16 & 7,3 & 3,77 & 7,01 & 23,34 \\
\hline Cultivar & NGE & MGE & MMG & PROD & IC \\
\hline BRS 264 & $32,33 \mathrm{ab}$ & $1,09 \mathrm{a}$ & $33,77 \mathrm{a}$ & $5693,94 \mathrm{a}$ & $0,47 \mathrm{a}$ \\
BRS 394 & $30,13 \mathrm{ab}$ & $0,91 \mathrm{ab}$ & $30,99 \mathrm{ab}$ & $4996,74 \mathrm{a}$ & $0,43 \mathrm{ab}$ \\
Tbio Audaz & $34,86 \mathrm{a}$ & $0,79 \mathrm{~b}$ & $22,55 \mathrm{~b}$ & $4178,80 \mathrm{a}$ & $0,34 \mathrm{~b}$ \\
Tbio Sonic & $27,27 \mathrm{~b}$ & $0,98 \mathrm{ab}$ & $35,81 \mathrm{a}$ & $4847,37 \mathrm{a}$ & $0,44 \mathrm{a}$ \\
\hline $\mathrm{p}$ & 0,03 & 0,03 & 0,01 & 0,09 & 0,01 \\
\hline CV (\%) & 9,78 & 12,04 & 12,8 & 14,74 & 10,14 \\
\hline
\end{tabular}

'Semeadura em 14 de fevereiro. CR: Comprimento da ráquis da espiga (cm); NGE: Número de grãos por espiga; NESP: número de espiguetas por espiga; NESPF: número de espiguetas férteis por espiga; NESPIN: número de espiguetas inférteis por espiga; MGE: massa de grãos por espiga (g); NES: número de espigas por metro quadrado; MMG: massa de mil grãos (g); PROD: produtividade de grãos $\left(\mathrm{kg} \mathrm{ha}^{-1}\right)$; IC: índice de colheita. $p$ : valor da probabilidade do teste $\mathrm{F} ; \mathrm{CV}$ : coeficiente de variação da parcela; Médias seguidas da mesma letra não diferem entre si pelo teste de Tukey $(p<0,05)$.

Os parâmetros do rendimento individual de espigas de trigo variaram de maneira significativa entre as cultivares estudadas (Tabela 3). Espigas de BRS 394 e Tbio Audaz apresentaram maior comprimento da ráquis, o que resultou em maior número de espiguetas para Tbio Audaz, embora o número de espiguetas inférteis também tenha aumentado nessa cultivar. O maior número de grãos por espiga foi observado para Tbio Audaz, embora não tenha diferido de BRS 264 e BRS 394. Contudo, esta cultivar apresentou os menores valores de massa de grãos por espiga e massa de mil grãos, enquanto as demais cultivares não diferiram entre si. A relação entre os componentes de produção estudados parece estabelecer comportamento de plasticidade produtiva entre as cultivares, o que explica a ausência de diferenças para os 
valores de produtividade de grãos considerando o nível de confiança utilizado para a comparação de médias $(p<0,05)$.

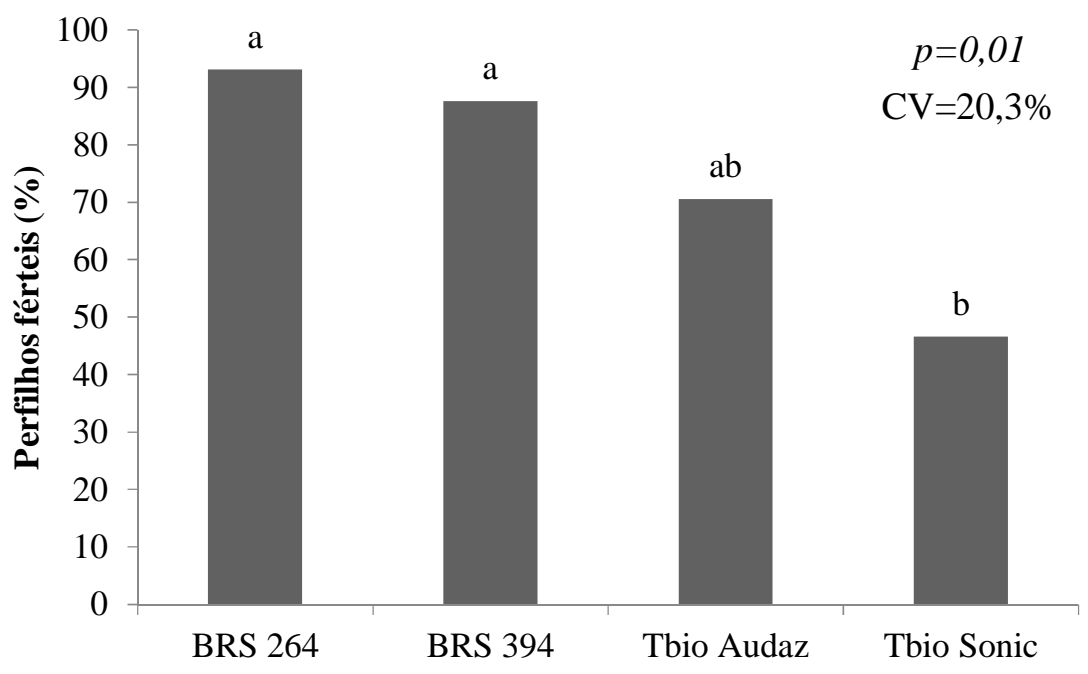

Figura 4. Porcentagem de perfilhos férteis de cultivares de trigo em safrinha ${ }^{1}$ no Planalto Catarinense. Curitibanos (SC), 2018. ${ }^{1}$ Semeadura em 14 de fevereiro.

Figure 4. Percentage of fertile tillers of wheat cultivars for off-season ${ }^{1}$ crops in the Santa Catarina Plateau. Curitibanos (SC), 2018. ${ }^{1}$ Sowing on February $14^{\text {th }}$.

A relação entre os componentes de produção apresentados pode ser explicada com base na performance das cultivares estudadas durante todo o período de desenvolvimento. A maior duração do período entre emergência e antese observada para Tbio Audaz (Figura 3b) parece ter afetado diretamente 0 número de grãos por espiga desta cultivar (Tabela 3). A quantidade de carboidratos solúveis acumulados no colmo das plantas neste período, especialmente após o final do perfilhamento, possui efeito direto sobre o número de espiguetas e sobre o número de grãos por espiguetas de trigo (DUGGAN et al. 2005, DRECCER et al. 2013). Por outro lado, Tbio Audaz apresentou drástica redução no período entre a antese e a maturação de plantas (Figura 3b), o que teve implicações diretas sobre o peso médio (massa de mil grãos) e, por consequência, a massa de grãos por espiga (ASSENG \& van HERWAARDEN 2003).
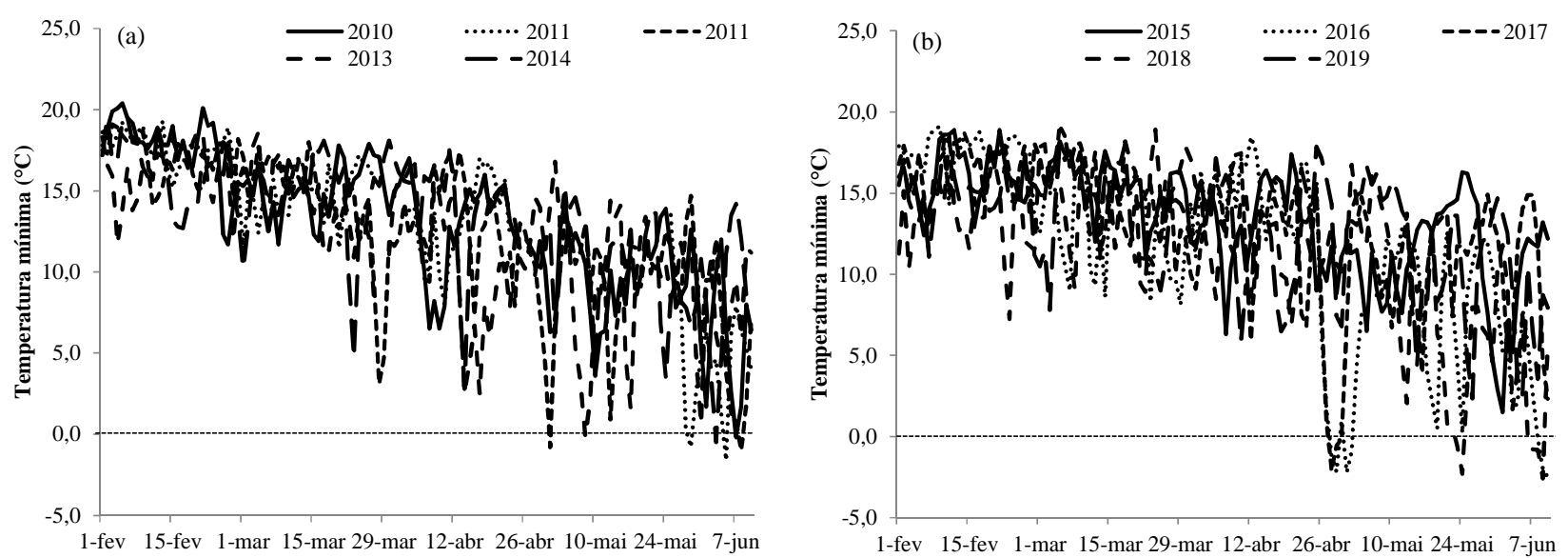

Figura 5. Série histórica de valores de temperaturas mínimas entre o início de fevereiro e o primeiro decêndio de junho nos últimos 10 anos. Curitibanos, SC, 2019. Dados entre 2010 e 2015 (a) provenientes do Instituto Nacional de Meteorologia (INMET). Dados entre 2016 e 2019 (b) provenientes do Centro de Informações de Recursos Ambientais e de Hidrometeorologia de Santa Catarina CIRAM/EPAGRI.

Figure 5. Historical series of minimum temperature values between the beginning of February and June $10^{\text {th }}$ over the last 10 years. Curitibanos,SC, 2019. Data between 2010 and 2015 (a) obtained from the Instituto Nacional de Meteorologia (INMET). Data between 2016 and 2019 (b) obtained from the Centro de Informações de Recursos Ambientais e de Hidrometeorologia de Santa Catarina CIRAM/EPAGRI. 
Os níveis de produtividade de grãos (Tabela 3) obtidos no presente estudo são considerados bastante adequados, principalmente quando comparados com os valores médios obtidos para o estado de Santa Catarina e mesmo em nível nacional (CONAB 2019). Os níveis de produtividade das cultivares BRS 264 e BRS 394 são semelhantes ou mesmo superiores aos obtidos por cultivares de trigo em condições de Cerrado brasileiro (ALBRECHT et al. 2007, SÓ e SILVA et al. 2008, COELHO et al. 2010). Analisando-se a série histórica de dados climáticos para o período entre fevereiro e o primeiro decêndio de junho entre 2010 e 2019, observa-se que a ocorrência de temperaturas abaixo de $0 \stackrel{\circ}{\circ}$ é baixa para o período de condução do ensaio, considerando o ciclo médio de 100 dias entre emergência e a colheita das plantas (Figura 5). Neste sentido, os resultados obtidos no presente estudo têm potencial para alavancar o desenvolvimento de novas pesquisas visando explorar a janela de safrinha para o cultivo de grãos na região do Planalto Catarinense. Por fim, considerando o potencial de adaptação da cultura do trigo para safrinha na região, um desafio a ser superado passa a ser a adequação da janela de cultivo da safra de verão, através do ajuste de épocas de semeadura e do ciclo dos materiais utilizados.

\section{CONCLUSÃO}

As cultivares de trigo estudadas apresentaram desempenho agronômico satisfatório para cultivo em safrinha no Planalto Catarinense para semeadura em 14 de fevereiro.

\section{REFERÊNCIAS}

AKTER N \& ISLAM MR. 2017. Heat stress effects and management in wheat. A review. Agronomy for Sustainable Development 37: 37.

ALBERTO CM et al. 2009. Resposta à vernalização de cultivares brasileiras de trigo. Bragantia 68: 535-543.

ALBRECHT JC et al. 2007. Adaptabilidade e estabilidade de genótipos de trigo irrigado no Cerrado do Brasil Central. Pesquisa Agropecuária Brasileira 42: 1727-1734.

ALMEIDA ML et al. 2004. Tiller emission and dry mass accumulation of wheat cultivars under stress. Scientia Agricola 61: 266-270.

ASSENG S \& van HERWAARDEN AF. 2003. Analysis of the benefits to wheat yield from assimilates stored prior to grain filling in a range of environments. Plant Soil 56: 217-229.

BRASIL. 2019. Ministério da Agricultura, Pecuária e Abastecimento. Zoneamento Agrícola de Risco Climático. Disponível em: <http://indicadores.agricultura.gov.br/zarc/index.htm>. Acesso em: 20 ago. 2019.

CARGNIN A et al. 2006. Tolerância ao estresse térmico em genótipos de trigo. Pesquisa Agropecuária Brasileira 41: 1269-1276.

CARGNIN A et al. 2008. Progress in breeding of irrigated wheat for the Cerrado region of Brazil. Crop Breeding and Applied Biotechnology 8: 39-46.

CONAB. 2019. Companhia Nacional de Abastecimento. Acompanhamento da safra brasileira de grãos - Safra 2018/19 Brasília: CONAB. p.1-104. (Décimo primeiro levantamento).

CLIMATE-DATA. 2018. Dados Climáticos para cidades mundiais. Oedheim: CLIMATE-DATA. Disponível em: <http://pt. climate-data.org/>. Acesso em: 20 ago. 2019.

COELHO MAO et al. 2010. Avaliação da produtividade de trigo (Triticum aestivum L.) de sequeiro em Minas Gerais. Bioscience Journal 26: 717-723.

CUNHA GR et al. 2006. Regiões de adaptação para trigo no Brasil. Passo Fundo: Embrapa Trigo. 10p. (Circular Técnica Online 20).

DRECCER MF et al. 2013. Developmental and growth controls of tillering and water-soluble carbohydrate accumulation in contrasting wheat (Triticum aestivum L.) genotypes: can we dissect them? Journal of Experimental Botany 64: 143160.

DUGGAN BL et al. 2005. Agronomic evaluation of a tiller inhibition gene (tin) in wheat. I. Growth and partitioning of assimilate. Australian Journal of Agricultural Research 56: 179-186.

FAO. 2018. Food and Agriculture Organization of the United Nations. Food Outlook: biannual report on global food markets. Roma: FAO. 169p.

FIOREZE SL \& RODRIGUES JD. 2012. Perfilhamento do trigo em função da aplicação de regulador vegetal. Revista Brasileira de Ciências Agrária 7: 750-755.

FIOREZE SL et al. 2019. Componentes produtivos do trigo em função da temperatura no período de diferenciação de espiguetas. Revista de Ciências Agroveterinárias 18: 24-32.

KUMAR RR et al. 2017. Exploring the heat-responsive chaperones and microsatellite markers associated with terminal heat stress tolerance in developing wheat. Functional \& Integrative Genomics 17: 621-640.

LARGE EC. 1954. Growth stages in cereals illustration of the Feeks scales. Plant Pathology 4: 128-129.

MACIEL JLN. 2011. Magnaporthe oryzae, the blast pathogen: current status and options for its control. CAB Reviews: Perspectives in Agriculture, Veterinary Science, Nutrition and Natural Resources 6: 1-8.

OCHAGAVÍA H et al. 2018 Dynamics of leaf and spikelet primordia initiation in wheat as affected by Ppd-1a alleles under field condition. Journal of Experimental Botany 69: 2621-2631. 
PASINATO A et al. 2018. Potential area and limitations for the expansion of rainfed wheat in the Cerrado biome of Central Brazil. Pesquisa Agropecuária Brasileira 53: 779-790.

PEREIRA JF et al. 2019. Improved drought tolerance in wheat is required to unlock the production potential of the Brazilian Cerrado. Crop Breeding and Applied Biotechnology 19: 217-225.

POERSCH-BORTOLON LB et al. 2016. Gene expression analysis reveals important pathways for drought response in leaves and roots of a wheat cultivar adapted to rainfed cropping in the Cerrado biome. Genetics and Molecular Biology 39: 629-645.

ROBERTSON MJ et al. 1996. Temperature response of vernalization in wheat: modelling the effect on the final number of mainstem leaves. Annals of Botany 78: 371-381.

SANTOS HG et al. 2018. Sistema Brasileiro de Classificação de Solos. 5o ed. Brasília: Embrapa. 356p.

SÓ e SILVA M et al. 2008. BRS 254: Wheat cultivar for irrigated conditions. Crop Breeding and Applied Biotechnology 8: 96-98.

VALÉRIO IP et al. 2009. Fatores relacionados à produção e desenvolvimento de afilhos em trigo. Semina 30: 12071218.

VALÉRIO IP et al. 2013. Seeding density in wheat: the more, the merrier? Scientia Agricola 70: 176-184. 